\title{
INFECÇÃO RELACIONADA À ASSISTÊNCIA À SAÚDE EM CIRURGIAS LIMPAS
}

Paloma Helena Sanches da Silva ${ }^{1}$, Nathália das Graças Dorneles Coelho ${ }^{2}$, Breno Curty Barbosa ${ }^{3}$, Pablo Herthel de Carvalho ${ }^{4}$, Patrícia Maria Coletto Freitas ${ }^{5}$

1 Residente em Clínica Cirúrgica em Animais de Companhia da Universidade Federal de Minas Gerais, Belo Horizonte-MG, Brasil, (palomahelena.vet@gmail.com).

2 Mestranda em Ciência Animal pela Universidade Federal de Minas Gerais.

3 Doutorando em Ciência Animal pela Universidade Federal de Minas Gerais.

4 Médico Veterinário da Escola de Veterinária da Universidade Federal de Minas Gerais.

5 Docente do Departamento de Clínica e Cirurgia Veterinárias da Universidade Federal de Minas Gerais.

\section{Recebido em: 06/04/2018 - Aprovado em: 10/06/2018 - Publicado em: 20/06/2018} DOI: 10.18677/EnciBio_2018A55

\begin{abstract}
RESUMO
Infecção relacionada com assistência à saúde (IRAS) é atribuída aos quadros adquiridos tanto no momento da admissão em ambientes de atenção à saúde, quanto durante a internação, e até mesmo após alta médica, sendo assim, correlacionada com a permanência hospitalar. $\mathrm{Na}$ rotina cirúrgica veterinária, pacientes tanto hígidos quanto imunocomprometidos, tornam-se susceptíveis. Ressalva-se, que a ferida cirúrgica infectada por microrganismos endógenos ou exógenos, com classificação de multirresistentes ou não, pode desencadear quadros sépticos. Denomina-se infecção no sítio cirúrgico (ISC), a colonização da ferida cirúrgica por microrganismos, sendo sua ocorrência no pós-operatório, uma das principais complicações relacionadas à IRAS. Os principais fatores que podem levar a ISC estão ligados ao pré, trans e pós-operatório. Os médicos veterinários que atuam diretamente em ambiente hospitalar, devem estar preparados para prevenir e tratar casos de ISC de maneira integrada e dinâmica. Entre as ferramentas importantes nesse processo, destacam-se os programas multidisciplinares de Antibiotic Stewardship associados ao desenvolvimento de técnicas diagnósticas rápidas e ao incentivo de medidas consagradas para o controle da infecção hospitalar. Objetiva-se com o presente trabalho ressaltar os principais fatores de risco, medidas profiláticas, e o programa Antibiotic Stewardship, para o controle da ISC.
\end{abstract}

PALAVRAS-CHAVE: Antibiotic Stewardship; Ferida Cirúrgica; Infecção Nosocomial

\section{INFECTION RELATED TO HEALTH CARE IN CLEAN SURGERIES - REVIEW OF LITERATURE}

\begin{abstract}
Health-care-related infection (IRAS) is attributed to the acquired cadres both at the time of admission to health care settings and during hospitalization, and even after medical discharge, thus correlating with hospital stay. In the veterinary surgical routine, both healthy and immunocompromised patients become susceptible. It should be noted that the surgical wound infected by endogenous or exogenous
\end{abstract}


microorganisms, classified as multiresistant or not, can trigger septic conditions. Infection in the surgical site (ISC) is called colonization of the surgical wound by microorganisms, and its occurrence in the postoperative period is one of the main complications related to IRAS. The main factors that can lead to SSI are related to pre, trans and postoperative. Veterinarians operating directly in the hospital environment should be prepared to prevent and treat ISC cases in an integrated and dynamic manner. Among the important tools in this process are the multidisciplinary Antibiotic Stewardship programs associated with the development of rapid diagnostic techniques and the encouragement of established measures for the control of hospital infection. The objective of this work is to highlight the main risk factors, prophylactic measures, and the Antibiotic Stewardship program, for ISC control.

KEYWORDS: Antibiotic Stewardship, Surgical Wound, Nosocomial Infection.

\section{INTRODUÇÃO}

Em medicina humana, os termos infecção hospitalar ou infecção nosocomial encontram-se desatualizados, estes foram substituídos por infecção relacionada à assistência à saúde (IRAS) (HORAN et al., 2008). A IRAS é definida como qualquer infecção, que o paciente adquire a partir da admissão em ambientes de atenção à saúde, gerando maior morbidade e mortalidade em imunocomprometidos, endocrinopatas, pós-cirúrgicos, paciente com extensas áreas de queimaduras e aqueles submetidos a cuidados em unidade de terapia intensiva (STULL; WEESE, 2015).

Dessas infecções adquiridas, $15 \%$ são representadas por infecções de sítio cirúrgico (ISC), correspondendo assim, a terceira complicação infecciosa mais comum dentro dos ambientes hospitalares, segundo a OMS (2009). Outras complicações das IRAS envolvem a circulação sanguínea, sistemas urinário e respiratório (HORAN et al., 2008) e, segundo Stull e Weese (2015) também apresentam-se em medicina veterinária com essa distribuição.

Os constantes estudos na medicina, relacionados à ISC, no que diz respeito a identificação de causa, tratamento, profilaxia e controle, tem levado os profissionais da medicina veterinária, a se posicionar de forma semelhante. Entretanto, esse conhecimento ainda é limitado pela maioria dos médicos veterinários, sendo um assunto emergente na área, uma vez que torna-se um risco à saúde não só dos pacientes envolvidos, mas também dos profissionais que participam da rotina clínica (STULL; WEESE, 2015).

A ISC pode ocorrer tanto em pacientes hígidos, quanto imunocomprometidos, haja vista que a formação da ferida cirúrgica propicia a quebra das barreiras biológicas. Sabe-se que os fatores de risco envolvem paciente (SANTOS; KEMP, 2011), ambiente, e microrganismos (FERNANDO et al., 2015). Procedimentos hospitalares realizados desde admissão, tempo prolongado de anestesia, longo período de internação, submissão há procedimentos cirúrgicos e falta de adesão às condutas de higiene, como lavagem das mãos, são fatores fundamentais para aumento da morbimortalidade (SILVA; BARBOSA, 2012).

Frente esse panorama mundial de ISC, um dos projetos promissores atuais, no combate a resistência bacteriana é o Antibiotic Stewardship, ou seja, programa multidisciplinar de gerenciamento de antibióticos (GEORGE; MORRIS, 2010). O qual deve ser implantado de acordo com as realidades das unidades de saúde, em associação com as técnicas consagradas de controle da infecção hospitalar, e técnicas diagnósticas rápidas, de elevada especificidade e sensibilidade, como a reação em cadeia da polimerase (PCR) Multiplex (AYDEMIR et al., 2014). 


\section{INFECÇÃO DO SÍTIO CIRÚRGICO}

Os termos colonização e infecção são divergentes, o primeiro é caracterizado pela presença de microrganismos em um determinado local, seja inanimado ou não, sem multiplicação dos agentes, e logo, sem causar alterações no hospedeiro. $O$ segundo por sua vez, relaciona-se a presença de microrganismos no paciente no qual há multiplicação dos mesmos em tecidos, órgãos ou cavidades, resultando em reações imunológicas, com desequilíbrio da produção de citocinas pró e antiinflamatórias (JOHNSON, 2002).

Estudo realizado por Nazarali et al. (2015) em cães submetidos a cirurgia de osteotomia e nivelamento do platô tibial, procedimento considerado limpo foi observado ISC causado por agente residente da microbiota tegumentar Staphylococcus Pseudintermedius, porém com alto padrão de resistência aos agentes antimicrobianos, incluindo a meticilina.

Uma vez instalada a ISC, a qual consiste de um processo infeccioso em tecidos, órgãos ou cavidades manipulados durante a intervenção cirúrgica, pode-se observar sua manifestação até um ano depois da execução, como nos casos envolvendo o uso de próteses (CDC, 2011). Dependendo da localização do tecido acessado, a ISC pode ser classificada em três categorias distintas: incisional superficial, na qual a incisão é realizada em pele e subcutâneo; incisional profunda, quando a incisão envolve fáscia e/ou músculos; e incisional orgão/cavidade, cujo órgão e/ou cavidade são abordadas cirurgicamente (CDC, 2011; ANVISA, 2013).

Alguns critérios são importantes para atentar e diagnosticar infecção presente no sítio cirúrgico, dentre eles, fatores como o tempo, localização anatômica, presença de secreção purulenta, aumento da temperatura, aumento da sensibilidade local, leucocitose e deiscência espontânea. $O$ isolamento do agente infeccioso associado aos sinais destacados anteriormente são confirmatórios para ISC (Figura 1) (ANVISA, 2013).

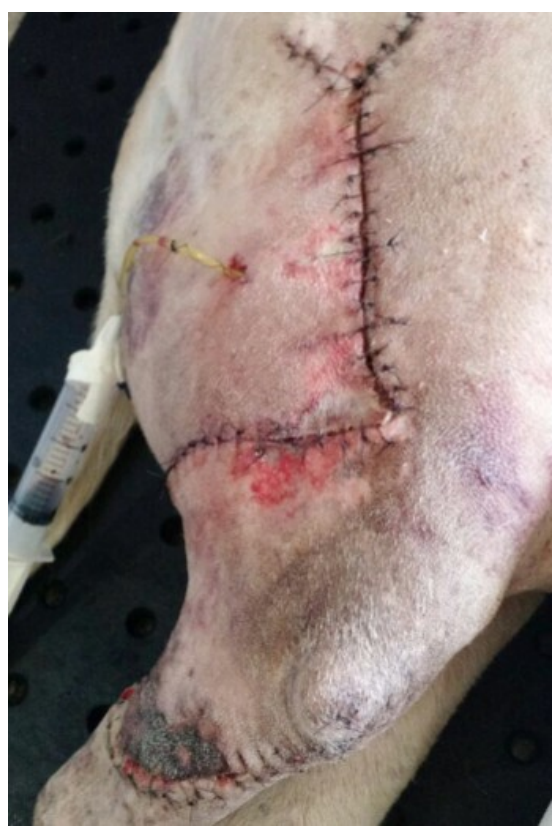

FIGURA 1 Infecção em ferida cirúrgica limpa, 72 horas após a exérese de neoplasia em membro posterior direito de um cão, macho, 9 anos de idade, atendido no Setor de Clínica Cirúrgica da Escola de Veterinária da Universidade Federal de Minas Gerais. Fonte: Hospital Veterinário da Universidade Federal de Minas Gerais. 


\section{FATORES DE RISCO}

Os fatores de risco podem ser classificados em três grupos: pré-operatório, trans-operatório e pós-operatório (SANTOS; KEMP, 2011).

\section{FATORES DE RISCO PRÉ-OPERATÓRIOS}

Os fatores de risco pré-operatório estão relacionados às características intrínsecas ao paciente dentre eles, pode-se citar sua condição de saúde, idade, estados nutricional e imunológico, classificação do risco cirúrgico pela avaliação préanestésica da American Society of Anesthesiologists (ASA), além do tempo de internação pré-operatória (CDC, 2013).

O tempo de internação pré-operatória é proporcional ao risco de colonização do paciente por bactérias presentes no ambiente hospitalar (SANTOS; KEMP, 2011). Em humanos, procedimentos cirúrgicos limpos apresentaram um aumento na taxa de infecção do sítio cirúrgico, quando o período de internação pré-operatória foi prolongado, por isso, recomenda-se que em cirurgias eletivas, a internação préoperatória não ultrapasse 24 horas (PEREIRA et al., 2015; ANVISA, 2017).

\section{FATORES DE RISCO TRANS-OPERATÓRIOS}

Os fatores de risco trans-operatórios estão relacionados com as condições do ambiente cirúrgico, como a movimentação de pessoas, grau de contaminação do procedimento executado, preparo da equipe e do paciente, técnicas de antissepsia e assepsia, além do tempo de duração do procedimento (BARBOSA et al., 2011).

As diretrizes sobre o ambiente cirúrgico do Conselho Federal da Medicina Veterinária através da RESOLUÇÃO $\mathrm{N}^{\circ} 1.015 / 2012$, definem normas para que tais procedimentos possam ser realizados de forma segura para o paciente e para 0 profissional. Entretanto, sabe-se que esses locais, mesmo respeitando as exigências legais, tornam-se contaminados por agentes endógenos veiculados pelos pacientes. Ato contínuo, acarreta contaminação de superfícies e equipamentos, e dessa forma contribuem para infecção no sítio cirúrgico, uma vez que, diversos microrganismos podem ser disseminados no ambiente. É recomendado que se tenha um número reduzido de pessoas, visando minimizar os riscos de ISC, ao reduzir o número de partículas em suspensão (CORSINI et al., 2014).

Em relação ao grau de contaminação do procedimento cirúrgico a ser executado, de acordo com os critérios propostos pelo Ministério da Saúde (Portaria 2.616/1998), feridas cirúrgicas podem ser classificadas em limpa, limpacontaminada, contaminada, suja e/ou infectada.

As feridas limpas, as quais são caracterizadas pela ausência de infecção no sítio cirúrgico, são aquelas que não apresentam falhas nas técnicas assépticas ou quando os sistemas digestório, respiratório, biliar e geniturinário não forem invadidos durante a cirurgia, o índice de infecção esperado no sítio cirúrgico, preconizado pelo CDC é de até $5 \%$. Determinadas cirurgias limpas, quando realizada sob condições assépticas e em pacientes saudáveis, normalmente possuem um sítio cirúrgico não associado a infecção pós-operatória (MARTINS, 2001), embora se saiba que há contaminação bacteriana, é esperada em graus variáveis durante qualquer procedimento cirúrgico. Entretanto, alguns estudos em medicina veterinária demonstram elevações nessas taxas. Outros estudos têm demonstrado que as cirurgias ortopédicas tem apresentado elevadas taxas de ISC (MURTA et al., 2015).

A ferida limpa-contaminada é aquela em que há abordagem do lúmen em órgãos ocos, entretanto, estando a infecção sob controle, sendo que o risco de ISC pode variar de $3 \%$ a $11 \%$. Já as feridas contaminadas são oriundas de procedimentos cirúrgicos que resultam em algum extravasamento de conteúdo dos ENCICLOPÉDIA BIOSFERA, Centro Cientifico Conhecer - Goiânia, v. 15 n.27; p. 85 
mesmos órgãos, bem como quebra da técnica asséptica, o que leva a um alto risco de infecção variando de $10 \%$ a $17 \%$. Finalmente, feridas sujas e/ou infectadas, englobam aquelas realizadas em presença de material purulento, de tecidos desvitalizados e em vísceras perfuradas. Espera-se assim, uma elevada taxa de infecção, acima de 27\% (CDC, 2011).

Outro fator de risco para infecção inclui o preparo do paciente para a intervenção cirúrgica. Neste contexto, recomenda-se o banho um dia antes da cirurgia, com a intenção de reduzir a microbiota transitória da pele, ocasionando assim, uma possível redução da ISC (SANTOS; KEMP, 2011). Outro ponto importante, é a tricotomia da área a ser incisada que, segundo a Anvisa (2017), deve ser realizada imediatamente antes da intervenção cirúrgica, com uso de instrumentos menos abrasivos a pele, como a tesoura ou aparador elétrico. O curto intervalo entre a tricotomia e a incisão cirúrgica, favorece a não proliferação bacteriana na pele e logo, diminui os riscos de ISC (MEDEIROS; CARVALHO, 2016).

Quanto às técnicas de antissepsia anterior ao ato cirúrgico, sejam das mãos do cirurgião e do campo operatório, quando respeitadas, contribuem para a prevenção da ISC (CONCEIÇÃO et al., 2016). A microbiota presente nas mãos e antebraços do cirurgião, bem como na pele do paciente, pode ser reduzida utilizando-se solução degermante, seguido da solução alcoólica. Técnicas assépticas empregadas como a paramentação da equipe cirúrgica e materiais cirúrgicos devidamente esterilizados devem ser também preconizados e realizadas em todos os procedimentos cirúrgicos, de forma a reduzir a probabilidade de ISC (ANVISA, 2017).

O uso de antibióticos com finalidade profilática em cirurgias tem por finalidade atingir um nível de concentração antimicrobiana inibitória mínima desejada na área incisada e mantê-lo até o término do procedimento cirúrgico, para assim, conseguir impedir a proliferação de agentes patogênicos (FERNANDO et al., 2015). Whittem et al. (1999) defenderam esta ideia em cirurgias ortopédicas eletivas, nas quais a profilaxia antimicrobiana, pode ser aplicada ao se utilizar antibiótico 30 minutos antes do procedimento, não sendo necessária sua administração após este período, como medida de redução e controle da incidência de infecção do sítio cirúrgico. Entretanto, no estudo demonstrado por Murta et al. (2015), o uso de antibioticoterapia profilática em cirurgias consideradas limpas, não exerce efeito em reduzir a taxa de infecção, sendo o seu uso contra indicado nestes procedimentos.

O uso sem diretrizes de antibióticos em cirurgias limpas, pode contribuir para uma colonização bacteriana, seguida de infecção por microrganismos considerados multirresistentes (FERNANDO et al., 2015), haja vista, que bactérias que são relacionadas as infecções associadas à assistência à saúde, são consideradas resistentes aos principais fármacos antimicrobianos utilizados rotineiramente (STULL; WEESE, 2015). Contribuem de forma significativa para a ISC, a concentração e a capacidade de virulência desses microrganismos (SANTOS; KEMP, 2001).

Na medicina veterinária, os principais agentes encontrados são Acinetobacter $\mathrm{sp}$, Enterobacteriaceae produtora de $\beta$-lactamase (FERNANDO et al., 2015), Pseudomonas aeruginosa (ISHII et al., 2011), Salmonella sp. (PLESSAS et al., 2013) e Staphylococcus Aureus resistente à meticilina (STULL; WEESE, 2015). Estudos realizados em hospitais veterinários (SFACIOTTE et al., 2014), relataram a ocorrência de resistência bacteriana a antibióticos como penicilinas, amoxicilina, ampicilina, entre outros. Tal panorama está intimamente relacionado à utilização 
profilática e empírica de antimicrobianos no pré e trans-cirúrgico, o que aumenta a pressão de seleção a resistência (KOHL et al., 2016).

\section{FATORES PÓS-OPERATÓRIOS}

São classificados nesse grupo, os fatores que se relacionam principalmente aos cuidados com a ferida cirúrgica, bem como procedimentos de suporte, durante a internação. O manejo adequado da ferida cirúrgica no pós-operatório e os cuidados durante sua manipulação e tratamento, podem influenciar na redução da ISC (BONAl et al., 2016). A limpeza diária e a manutenção de uma ferida livre de secreções e excreções corpóreas merecem atenção, uma vez que microrganismos podem ser carreados através de fômites para a ferida, tornando-a contaminada.

A higienização das mãos e o uso de luvas antes e após sua manipulação é importante para reduzir os riscos de ISC (ANVISA, 2017). A grande maioria dos profissionais não se lembra de tal fato, prosseguindo com o atendimento e disseminando microrganismos, podendo tornar-se fonte potencial de infecção, principalmente, em pacientes imunocomprometidos (SIQUEIRA, 2013). A Portaria 2.616/1998 do Ministério da Saúde adota como medida preventiva, uma educação permanente em enfatizar a adesão dos profissionais de saúde à lavagem das mãos antes e após qualquer procedimento, que envolva a manipulação do paciente, além da padronização de como deve ser feita essa higienização.

Falhas durante a antissepsia e assepsia na execução de procedimentos invasivos contribuem para a infecção adquirida, devido ao fato do contato direto que o microrganismo pode ter com a circulação sanguínea do paciente, por meio do uso de dispositivos intravasculares. Como exemplo, a inserção de cateteres venosos periféricos, procedimento comum aos pacientes submetidos a cirurgias eletivas. Quando mantidos por um período maior que 72 horas em geral (Figura 2), sem o preparo e antissepsia adequada, no qual o cateter venoso é inserido no vaso sanguíneo, sem tricotomia e limpeza prévia, pode contribuir de forma significativa para que a infecção se instale (Figura 3), podendo levar a casos de sepse na medicina veterinária (ARIAS et al., 2013).

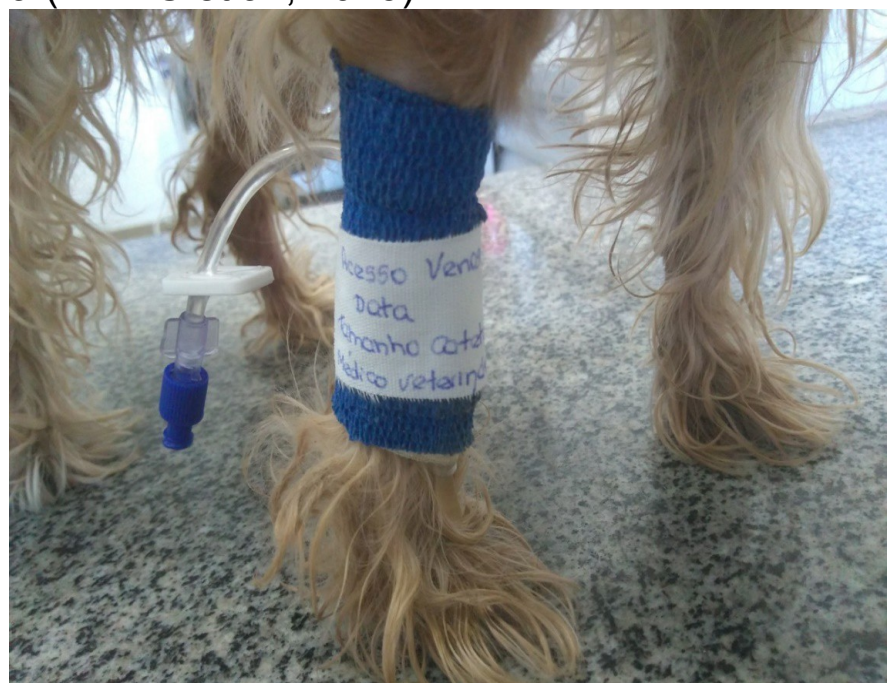

FIGURA 2: Identificação correta em venóclise da veia cefálica direita de um cão, yorkshire, 12 anos, contendo nome do médico veterinário responsável, data e diâmetro do cateter. Fonte: Setor de Emergência e Terapia Intensiva da Escola de Veterinária da Universidade Federal de Minas Gerais. 


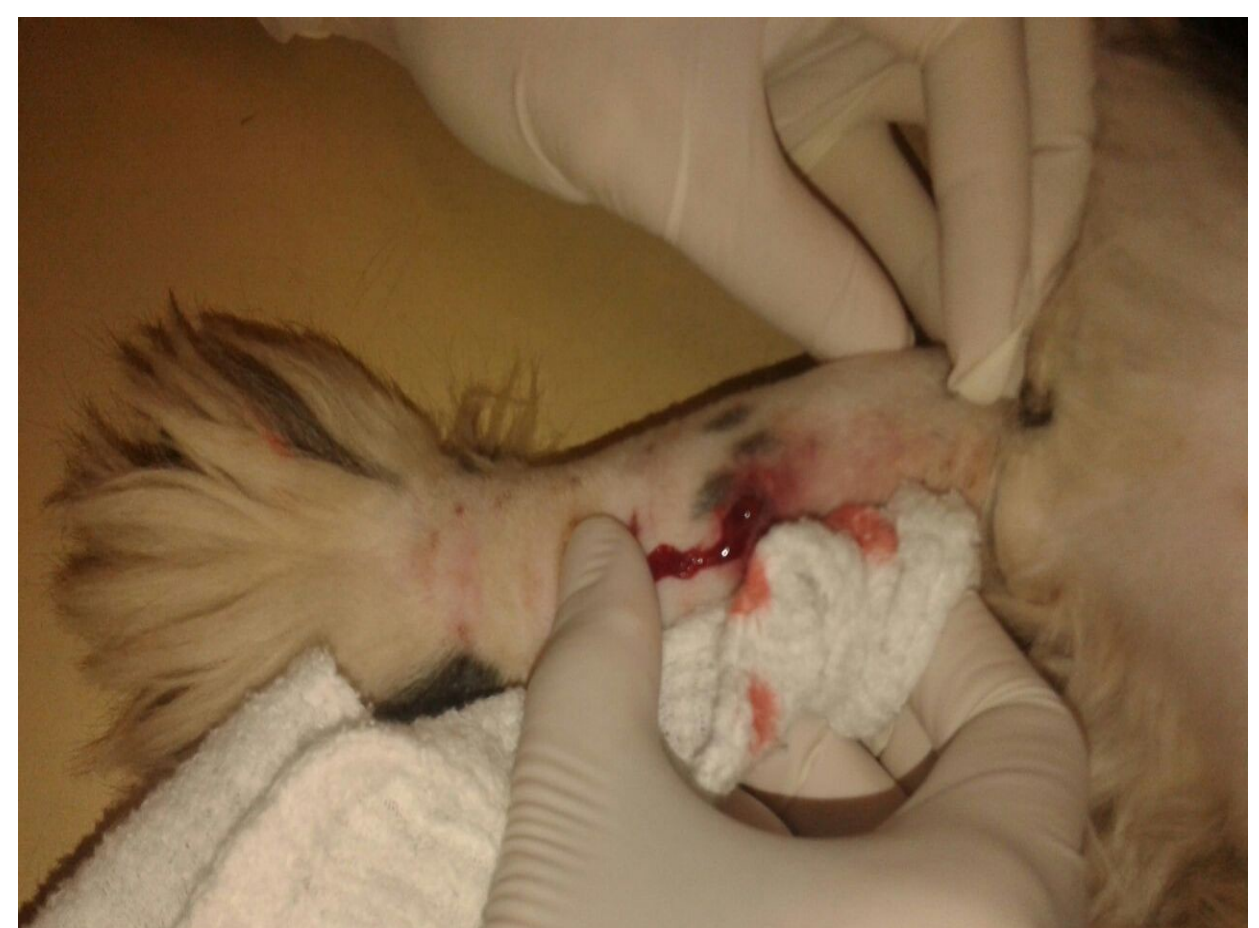

FIGURA 3: Drenagem de flegmão em membro anterior direito em um cão, Shih Tzu, macho, 5 anos de idade, após infecção de cateter venoso periférico inserido em veia cefálica. Fonte: Setor de Clínica Médica de Cães e Gatos da Escola de Veterinária da Universidade Federal Minas Gerais.

A cateterização vesical sem preconizar as técnicas de assepsia e antissepsia de pacientes internados como realização de tricotomia (Figura 4) torna-se uma fonte de entrada para a ascensão de bactérias ao trato urinário. Esses microrganismos podem ser endógenos, oriundos do períneo ou do reto, e até mesmo exógenos. A infecção ocorre, quando as bactérias formam um biofilme, associado ao fato da presença do dispositivo, dificultar a defesa natural do trato urinário (ANDERSON et al., 2014; STULL; WEESE, 2015).

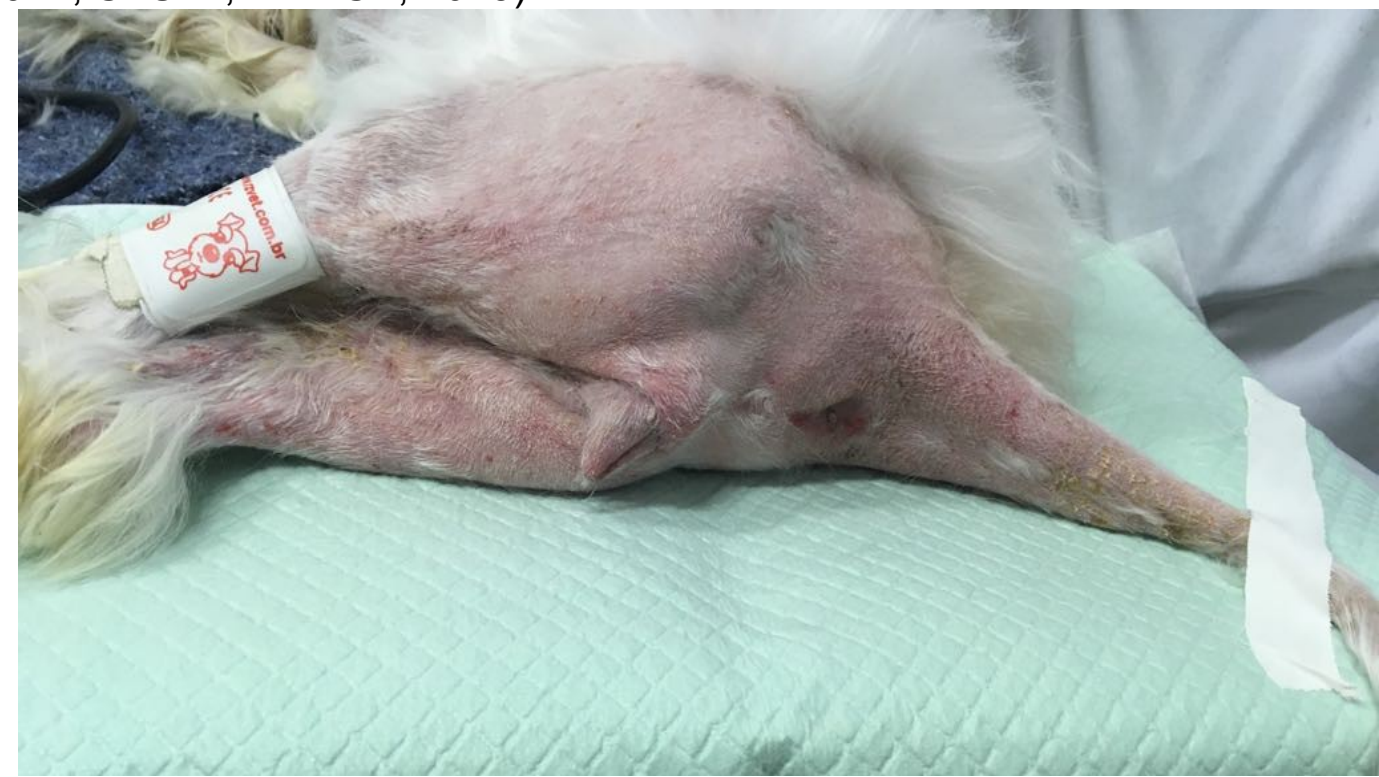

FIGURA 4: Tricotomia ampla da região perineal de cadela, maltês, 8 anos de idade, para posterior cateterização vesical. Fonte: Hospital Veterinário da Escola de Veterinária da Universidade Federal de Minas Gerais. 


\section{MEDIDAS DE PREVENÇÃO E CONTROLE}

Em razão da elevada morbidade e da alta mortalidade que as infecções adquiridas pela assistência à saúde podem causar, principalmente, naquelas que levam a infecções no sítio cirúrgico, é fundamental que se crie na medicina veterinária, assim como já estabelecida na medicina humana, um comitê de controle de infecção hospitalar $(\mathrm{CClH})$, com base em conhecimentos epidemiológicos. A criação de um Programa de Vigilância Epidemiológica dentro dos ambientes de clínicas e hospitais veterinários (CORSINI, 2014), teria como finalidade promover uma melhor monitoração e controle dos patógenos causadores de infecção e com isso, garantir qualidade nos serviços prestados à saúde dos animais. O programa poderia englobar também, aspectos gerais como limpeza adequada dos ambientes com produtos específicos em concentrações apropriadas, controle do fluxo de pessoas na sala de cirurgia, bem como a paramentação e o preparo correto da equipe cirúrgica (CORSINI, 2014), associado com conscientização, quanto à indicação apropriada dos antibióticos, preconizando-se, que sua prescrição seja criteriosa e baseada nos resultados dos exames de cultura e antibiograma (SFACIOTTE et al., 2014).

\section{USO RACIONAL DE ANTIMICROMIANOS EM ISC}

As ISC estão em destaque frente aos diversos tipos de infecções associadas à assistência à saúde, segundo a OMS (2009). Tal complicação, por levar ao aumento do tempo de internação e culminar em sepse, o que contribui para o uso prolongado e abusivo de antimicrobianos, com amplo espectro, em ambiente intrahospitalar (SILVA; BARBOSA, 2012). A utilização dessa classe terapêutica de maneira racional e adequada poderá contribuir para redução da mortalidade de pacientes com ISC, bem como, desaceleração da resistência bacteriana no mundo. Frente a esse panorama, o conhecimento do recurso multidisciplinar Antibiotic Stewardship direcionado ao tratamento de ISC, permite aumentar a probabilidade de êxito no combate a infecção e a resistência bacteriana (SHOUTEN; WAELE, 2017).

O panorama atual revela que $30-40 \%$ das prescrições de antimicrobianos nos centros de terapia intensiva humana são realizadas sem seguir as diretrizes mundiais de gerenciamento de antimicrobianos (BARTLETT, 2011), somado as prescrições desnecessárias de $50 \%$ dos antibióticos. Perspectivas futuras projetam que a partir do ano de 2050, a resistência a antibióticos apresentará maior taxa de mortalidade em comparação com o câncer, diabetes e a cólera, totalizando mais de 10 milhões de mortes no mundo a cada ano, além da limitação de ferramentas efetivas de combate as bactérias. Ao tratar ISC, o profissional precisa potencializar e dinamizar o uso do antibiótico que tem em mãos, uma vez, que o desenvolvimento de medicamentos para doenças infecciosas está inferior a velocidade de desenvolvimento da resistência bacteriana, principalmente contra bactérias gramnegativas (SHOUTEN; WAELE, 2017).

Antes de gerenciar os antibióticos no paciente crítico e em pacientes com ISC, é preciso entender que a prescrição antimicrobiana é um processo complexo, influenciado por múltiplos fatores, que variam entre países, hospitais e médicos. Dentre eles, destacam-se: experiência profissional, nível de conhecimento dos antibióticos, colaboração, comunicação, trabalho em equipe, diferenças socioculturais e socioeconômicas (HULSCHER et al., 2010).

O primeiro conjunto de recomendações para prescrição adequada, descreve os cuidados para uso de antimicrobianos em pacientes individualizados, alertando sobre a escolha correta do fármaco, o momento de administração, dose, intervalo, 
via de administração, duração do tratamento e desescalonamento. Um segundo grupo de recomendações, descreve as estratégias para assegurar a aplicação dessas etapas no processo de gerenciamento de antimicrobianos nos centros de terapia intensiva e em enfermarias pós-cirúrgicas, sendo dividido em dois grupos, o restritivo (restrição de formulações) e o persuasivo (educação continuada e feedback), com capacidade de garantir a melhora do uso de antibióticos (SHOUTEN; WAELE, 2017).

Um dos passos mais importantes para tratamento de ISC é o trabalho multidisciplinar, principalmente, em doenças infecciosas, haja vista, necessidade de cirurgiões, clínicos, farmacêuticos e intensivistas acrescentem suas próprias experiências profissionais, em associação com as diretrizes nacionais ou internacionais para administração de antimicrobianos (SHOUTEN; WAELE, 2017).

\section{ABORDAGEM SISTEMÁTICA NA PRESCRIÇÃO ANTIBIÓTICA}

No primeiro dia, deve-se buscar fundamentação clínica para início do antibiótico e sua documentação da escolha, assim como, realizar coleta de material para cultura microbiológica, de acordo com as normas locais elou internacionais, antes da terapia antimicrobiana empírica. Do segundo ao quinto dia, objetiva-se revisão do diagnóstico e tratamento, de acordo com a evolução clínica e os resultados microbiológicos, como culturas recém-adquiridas, a fim de potencializar e rastrear o tratamento (SCHOUTEN et al., 2012; SHOUTEN; WAELE, 2017).

A primeira etapa no processo de Antibiotic Stewardship, é desenvolver indicadores de qualidade, para medir o quanto a sua prescrição de antibiótico está sendo adequada. Essa etapa vai além de definir o uso apropriado de antimicrobiano, mas também para saber como ele pode ser validado de maneira confiável (SHOUTEN; WAELE, 2017).

A segunda etapa busca intervenções de manejo, e facilitar as prescrições de antimicrobianos, além de alterar os comportamentos individuais dos prescritores, para que o paciente possa receber o antibiótico no momento, dose, intervalo, via de administração e duração apropriados (SHOUTEN; WAELE, 2017).

$\mathrm{Na}$ terceira etapa deve-se compreender as principais variações do comportamento atual de prescritores, uma vez que mudanças comportamentais são difíceis de serem conquistadas. Sabe-se, que 57 determinantes podem influenciar na prática de prescrição específica em um hospital, subdivididos em sete categorias: 1. Fatores orientadores (Clareza das recomendações e as evidências dessas recomendações). 2. Fatores individuais dos profissionais de saúde (sensibilização e familiaridade com o tema ou habilidades necessárias para aderir). 3. Fatores do paciente (doença particular e as demandas recebidas e classificação dos antibióticos a serem oferecidos). 4. Interações profissionais (Comunicação). 5. Incentivos e recursos (sistema de informação influencia a adesão). 6. Capacidade de mudança organizacional (liderança capaz de fazer mudanças necessárias) 7. Fatores sociais, políticos e legais (Políticas financiadoras) (SHOUTEN; WAELE, 2017).

Por último, deve-se mapear as intervenções realizadas e selecionar as que apresentaram desenvolvimento positivo para implementação do programa de gerenciamento de antibióticos. Não há nenhuma intervenção fácil, que promova desenvolvimento positivo em todas as circunstâncias de implementação do programa de Antibiotic Stewardship. O desafio dessa etapa consiste em construir sistematicamente, uma avaliação cuidadosa das barreiras e facilitadores do projeto e investir em uma base teórica coerente, que associe os determinantes presentes às intervenções realizadas (SHOUTEN; WAELE, 2017). 
Um alvo prático e atual para ser atingido nos programas de Antibiotic Stewardship, é a melhora na tomada de decisão para interrupção da antibioticoterapia, já que a duração do tratamento, também é um fator determinante para aquisição de resistência a múltiplos fármacos. Embora muitas diretrizes recomendem uma duração de sete dias de antibioticoterapia, por medo de interromper, a média de duração desse tratamento se torna maior que 10 dias em muitas UTI's (SHOUTEN; WAELE, 2017).

Várias barreiras podem atrapalhar a implementação do Antibiotic Stewardship para tratamento de diversas infecções, dentre elas as ISC. Destaca-se, a escassez de corpo técnico, recursos financeiros limitados. Logo, para melhor aplicação dessas diretrizes nas unidades de saúde, os programas de Antibiotic Stewardship precisam ser adaptados às necessidades individuais das instituições e suas realidades de recursos (GEORGE; MORRIS, 2010).

\section{CONSIDERAÇÕES FINAIS}

A ISC está presente rotineiramente nas clínicas e hospitais veterinários, exigindo conhecimento do médico veterinário a respeito dos seus fatores predisponentes e recursos diagnósticos e terapêuticos. A implementação de programas multidisciplinares como Antibiotic Stewardship, permitem um melhor desfecho para os paciente submetidos a intervenção cirúrgica.

\section{REFERÊNCIAS}

AYDEMIR, O.; AYDEMIR, Y.; OZDEMIR, M. The role of multiplex PCR test in identification of bacterial pathogens in lower respiratory tract infections. Pakistan Journal of Medical Sciences, v. 30, n. 5, p. 1011-1016, 2014. Disponível em:

https://www.ncbi.nlm.nih.gov/pmc/articles/PMC4163223/pdf/pjms-301011.pdf > doi: $10.12669 /$ pjms.305.5098.

ANDERSON, D.J., PODGORNY, K., BERRIOS-TORRES, S.I., BRATZLER, D. W., DELLINGER, E. P., GREENE, L. et al. Strategies to Prevent Surgical Site Infections in Acute Care Hospitals. Infection control and hospital epidemiology: the official journal of the Society of Hospital Epidemiologists of America, v. 35, n.6, p. 605627, 2014. Disponível em https://www.ncbi.nlm.nih.gov/pmc/articles/PMC4267723/pdf/nihms-638942.pdf '

ARIAS, M. V. B.; AIELLO, G.; BATTAGLIA, L. A.; FREITAS, J. C. Estudo da ocorrência de infecção hospitalar em cães e gatos em um centro cirúrgico veterinário universitário. Pesquisa Veterinária Brasileira, v. 33, n. 6, p. 771-779, 2013. Disponível em: ‘ http://www.scielo.br/pdf/pvb/v33n6/14.pdf ’.

BARBOSA, M. H., LUIZ, R. B., ANDRADE, E. V., SILVA, Q. C. G., MATTIA, A. L. Ocorrência de infecção de sitio cirúrgico em cirurgias de urgência e emergência. Revista Mineira de Enfermagem, v. 15, n.2, p. 254-258, 2011. Disponível em * http://www.reme.org.br/exportar-pdf/33/v15n2a14.pdf >

BARTLETT, J.G. Antimicrobial stewardship for the community hospital: Practical tools \& techniques for implementation. Clinical Infectious Diseases, v. 53, n. 1, p. 4-7, 2011. Disponível em: < https://academic.oup.com/cid/article/53/suppl_1/NP/427051> doi: 
https://doi.org/10.1093/cid/cir554

BONAI, P. H. M., BERBER, G. C. M., JUNIOR, D. F. Infecção de sítio cirúrgico: Revisão. Scientific Electronic Archives, v. 9, n. 3, p. 147-160, 2016. Disponível em ‘http://www.seasinop.com.br/revista/index.php?

journal=SEA\&page=article\&op=view\&path $\% 5 B \% 5 D=282 \&$ path $\% 5 B \% 5 D=p d f$ >

BRASIL. AGÊNCIA NACIONAL DE VIGILÂNCIA SANITÁRIA. Critérios diagnósticos de infecção relacionada à assistência à saúde - Série segurança do paciente e qualidade em serviços de saúde, Brasília, 2013. Disponível em http://portal.anvisa.gov.br/documents/33852/3507912/Caderno+2+Crit

$\%$ C3\%A9rios+Diagn\%C3\%B3sticos+de+Infec\%C3\%A7\%C3\%A3o+Relacionada+ $\%$ C3\%A0+Assist\%C3\%AAncia+\%C3\%A0+Sa\%C3\%BAde/7485b45a-074f-4b348868-61f1e5724501

BRASIL. AGÊNCIA NACIONAL DE VIGILÂNCIA SANITÁRIA. Medidas de Prevenção de Infecção Relacionada à Assistência à Saúde - Série Segurança do Paciente e Qualidade em Serviços de Saúde, Brasília, 2017. Disponível em http://portal.anvisa.gov.br/documents/33852/3507912/Caderno+4+-

+Medidas+de+Preven $\% \mathrm{C} 3 \% \mathrm{~A} 7 \% \mathrm{C} 3 \% \mathrm{~A} 30+$ de+Infec

$\% \mathrm{C} 3 \% \mathrm{~A} 7 \% \mathrm{C} 3 \% \mathrm{~A} 30+$ Relacionada+\%C3\%A0+Assist $\% \mathrm{C} 3 \% \mathrm{AAncia}+\% \mathrm{C} 3 \% \mathrm{~A} 0+\mathrm{Sa}$

$\%$ C3\%BAde/a3f23dfb-2c54-4e64-881c-fccf9220c373 >

BRASIL. Ministério da Saúde. Portaria 2616, de 12 maio de 1998. Dispõe sobre a obrigatoriedade de Programas de Controle de Infecção Hospitalar e sua Estrutura e Atividades, Diário Oficial, Brasília, 13 maio 1988. Seção 1, p.133-135. Disponível em

http://bvsms.saude.gov.br/bvs/saudelegis/gm/1998/prt2616_12_05_1998.html >

CDC. Centers for diseade control and prevention, 2011. A public heath action plan to combat antimicrobial resistance, Atlanta: Centers for Disease Control and Prevention, 2011. 43p. Disponível em https://www.cdc.gov/drugresistance/actionplan/aractionplan.pdf

CDC. Centers for diseade control and prevention, 2013. Antibiotic resistance threats in the United States. Atlanta: Department of Health and Human Services, 2013. 113p. Disponível em - https://www.cdc.gov/drugresistance/pdf/arthreats-2013-508.pdf

CONCEIÇÃO, A. S. M. M., NETO, J. L. S., FREIRE, R. F., COSTA, P. P. C. Infecção pós-cirúrgica em felino- Relato de caso. Revista Brasileira de Higiene e Sanidade Animal, v. 10, n. 4, p. 754 - 771, 2016. Disponível em ‘http://www.higieneanimal.ufc.br/seer/index.php/higieneanimal/article/view/396/2169

CFMV - Conselho Federal de Medicina Veterinária . RESOLUÇÃO N¹.015/2012. 31 jan. 2013. Seção 1, p.172-173. Disponível em http://portal.cfmv.gov.br/lei/index/id/441 
CORSINI, C. M. M., BORGES, A. P. B., ALBERTO, D. S., JOSÉ, R. M., SILVA, C. H. $O$. Incidência de infecção do sítio cirúrgico e fatores de risco associados na clínica cirúrgica de pequenos animais. Arquivo Brasileiro de Medicina Veterinária e Zootecnia, v. 66, n. 3, p. 737-744, 2014. Disponível em http://www.scielo.br/pdf/abmvz/v66n3/0102-0935-abmvz-66-03-00737.pdf . doi: 10.1590/1678-41626092

FERNANDO, F. S.; SILVA, K. R.; VIGNOTO, V. K. C.; DE CONTI, J. B.; PACHALY, J. R; WOSIACKI, S. R. Avaliação microbiana de sítio cirúrgico relacionado ao tempo de procedimento e resistência a antimicrobianos em cães e gatos. Revista de Ciência Veterinária e Saúde Pública, v. 2, n.1, p. 26-33, 2015. Disponível em http://periodicos.uem.br/ojs/index.php/RevCiVet/article/view/Fernando/pdf_51 ’.

GEORGE, P.; MORRIS, A. M. Pro/Con Debate: Should Antimicrobial Stewardship Programs be Adopted Universally in the Intensive Care Unit?. Critical Care, p. 205211, v. $14, \quad 2010 . \quad$ Disponível em: https://www.ncbi.nlm.nih.gov/pmc/articles/PMC2875495/pdf/cc8219.pdf’. $\quad$ doi: https://doi.org/10.1186/cc8219.

HORAN, T. C.; ANDRUS, M.; DUDECK, M. A. CDC/NHSN surveillance definition of health care-associated infection and criteria for specific types of infections in the acute care setting. American Journal of Infection Control, v. 36, n. 5, p. 309-332, 2008. Disponível em: http://www.ajicjournal.org/article/S0196-6553(08)001673/fulltext '. doi: https://doi.org/10.1016/j.ajic.2008.03.002

HULSCHER, M.E.; GROL, R. P.; VAN DER MEER, J.W. Antibiotic prescribing in hospitals: a social and behavioural scientific approach. The Lancet Infectious Diseases, v. 10, p. 167-175, 2010. Disponível em: <https://ac.elscdn.com/S147330991070027X/1-s2.0-S147330991070027X-ain.pdf?_tid=5afc6145d482-4c8a-ad55-

88da50149a42\&acdnat $=1526394515$ 986caaefc08ab6f22fc3cd225120b58e>. doi: https://doi.org/10.1016/S1473-3099(10)70027-X.

ISHII, J.B.; FREITAS, J.C.; ARIAS, M.V.B. Resistência de bactérias isoladas de cães e gatos no Hospital Veterinário da Universidade Estadual de Londrina (20082009). Pesquisa Veterinária Brasileira, v. 31, n.6, p. 533-537, 2011. Disponível em: http://www.scielo.br/pdf/pvb/v31n6/a13v31n6.pdf. doi: http://dx.doi.org/10.1590/S0100-736X2011000600013

JOHNSON, J. A. Nosocomial infections. Veterinary Clinics of North America: Small Animal Practice, v. 32, n.5, p. 1101-1126, 2002. Disponível em: https://www.sciencedirect.com/science/article/pii/S0195561602000384? rdoc $=1 \&$ fmt=high\&_origin=gateway\&_docanchor=\&md5=b8429449ccfc9c301 59a5f9aeaa92ffb\&ccp=y '. doi: https://doi.org/10.1016/S0195-5616(02)00038-4

KOHL, T.; PONTAROLO, G. H.; PEDRASSANI, D. Resistência antimicrobiana de bactérias isoladas de amostras de animais atendidos em hospital veterinário. Saúde \& Meio Ambiente - Revista Interdisciplinar, v.5, n.2, p. 115-127, 2016. Disponível 
em: < http://www.periodicos.unc.br/index.php/sma/article/view/1197/690 >. doi: http://dx.doi.org/10.24302/sma.v5i2.1197

MARTINS, M.A. Manual de infecção hospitalar: Epidemiologia, prevenção e controle. $2^{\mathrm{a}}$ Ed. Belo Horizonte: MEDISI, 2001. p.1116.

MEDEIROS, A. M.; CARVALHO, M. D. F. Infecção em cirurgia. Journal of Surgical and Clinical Research, v. 7, n. 2, p. 60-73, 2016. Disponível em: https://periodicos.ufrn.br/jscr/article/view/11413/8047

MURTA, A. R.; ABREU, N. B.; CARLO REIS, E. C.; VALENTE, L. F.; GONÇALVES, G. P.; ELEOTÉRIO, R. B.; BORGES, A. P. B. Perfil epidemiológico e análise microbiológica da infecção de sítio cirúrgico em pacientes humanos e animais de companhia. Pesquisa Veterinária Brasileira, v. 35, n. 7, p. 652-658, 2015. Disponível em:< http://www.scielo.br/pdf/pvb/v35n7/1678-5150-pvb-35-07-00652.pdf doi: 10.1590/S0100-736X2015000700009

NAZARALI, A.; SINGH, A.; MOENS, N.M.; GATINEAU, M. Association between methicillin-resistant Staphylococcus pseudintermedius carriage and the development of surgical site infections following tibial plateau leveling osteotomy in dogs. Journal of the American Veterinary Medical Association, v. 247, n. 8, p. 909-916, 2015. Disponível em: https://avmajournals.avma.org/doi/abs/10.2460/javma.247.8.909? url_ver=Z39.88-2003\&rfr_id=ori\%3Arid\%3Acrossref.org\&rfr_dat=cr_pub\%3Dpubmed >. doi: https://doi.org/10.2460/javma.247.8.909

OMS. Segundo desafio global para a segurança do paciente: Manual - cirurgias seguras salvam vidas (orientações para cirurgia segura da OMS) / Rio de Janeiro: OPAS; Ministério da Saúde; ANVISA, 2009. Disponível em: http://bvsms.saude.gov.br/bvs/publicacoes/seguranca_paciente_cirurgias_seguras_s alvam_vidas.pdf

PEREIRA, H.O.; REZENDE, E.M.; COUTO, B.R.G.M. Tempo de internação préoperatório: um fator de risco para reduzir a infecção cirúrgica em fraturas de fêmur. Revista Brasileira de Ortopedia, v. 50, n. 6, p. 638-646, 2015. http://www.scielo.br/pdf/rbort/v50n6/pt_1982-4378-rbort-50-06-00638.pdf . doi: http://dx.doi.org/10.1016/j.rbo.2015.04.011

PLESSAS, I.N.; JULL, P. VOLK, H.A. A case of canine discospondylitis and epidural empyema due to Salmonella species. The Canadian Veterinary Journal, v. 54, n. 6 , p. 595-598, 2013. Disponível em: https://www.ncbi.nIm.nih.gov/pmc/articles/PMC3659457/pdf/cvj_06_595.pdf

SANTOS, J.S.; KEMP, R. Fundamentos básicos para a cirurgia e cuidados perioperatórios. Medicina, Ribeirão Preto, 44.1, 2-17, 2011. Disponível em: < http://revista.fmrp.usp.br/2011/vol44n1/Simp1_Fundamentos\%20para\%20as\%20t \%E9cnicas\%20b\%E1sicas\%20da\%20cirurgia.pdf

SCHOUTEN, J.; DE WAELE, J. J. Implementing Antimicrobial Stewardship in Critical Care: A Practical Guide. Annual Update in Intensive Care and Emergency Medicine, $\quad$ p. 15-25, 2017. Disponível em: < ENCICLOPÉDIA BIOSFERA, Centro Científico Conhecer - Goiânia, v.15 n.27; p. $94 \quad 2018$ 
https://www.researchgate.net/publication/315859345_Implementing_Antimicrobial_St ewardship_in_Critical_Care_A_Practical_Guide >. doi: 10.1007/978-3-319-51908$1 \_2$.

SFACIOTTE, R. A. P.; VIGNOTO, V. K. C.; WOSIACKI, S. R. Perfil de resistência antimicrobiana de isolados bacterianos de afecções clínicas do Hospital Veterinário da Universidade Estadual de Maringá. Revista de Ciência Veterinária e Saúde

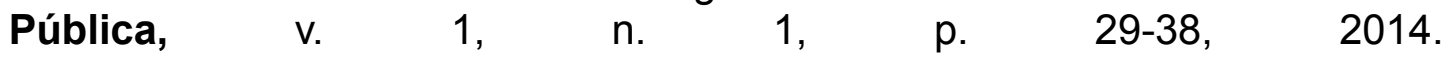
http://www.periodicos.uem.br/ojs/index.php/RevCiVet/article/view/23281/pdf_10

SILVA, Q.C.G.; BARBOSA, M.H. Fatores de risco para infecção de sítio cirúrgico em cirurgia cardíaca. Acta Paulista de Enfermagem, v. 25, n.2, p. 89-95, 2012. Disponível em: ‘ http://www.scielo.br/pdf/ape/v25nspe2/pt_14.pdf

SIQUEIRA, S.M.C. Higienização das mãos: medida de prevenção da infecção hospitalar. Revista Saúde.com, v. 9, n. 2, p. 341-347, 2013. Disponível em: http://www.uesb.br/revista/rsc/ojs/index.php/rsc/article/view/210/245 ’.

STULL, J.W.; WEESE, J.S. Hospital-Associated Infections in Small Animal Practice. Veterinary Clinics of North America: Small Animal Practice, v. 45, n. 2, p. 217233, 2015. Disponível em: https://www.sciencedirect.com/science/article/pii/S0195561614001879?via\%3Dihub . doi: https://doi.org/10.1016/j.cvsm.2014.11.009

WHITTEM T.L.; JOHNSON, A.L.; SMITH, C.W.; SCHAEFFER, D. J.; COOLMAN, B. R.; AVERILL, S. M.; COOPER, T. K.; MERKIN, G. R. Effect of perioperative prophylactic antimicrobial treatment in dogs undergoing elective ortophedic surgery. Journal of the American Veterinary Medical Association, v. 215, n. 2, p. 212-216, 1999. Disponível em:https://www.ncbi.nlm.nih.gov/pubmed/10416474. 